\title{
Surface Wave Imaging using Distributed Acoustic Sensing Deployed on Dark Fiber: Moving Beyond High Frequency Noise
}

\author{
Verónica Rodríguez Tribaldos ${ }^{1}$, Jonathan Ajo-Franklin ${ }^{1 *}$, Shan Dou ${ }^{4}$, Nathaniel J. Lindsey ${ }^{1,2}$, Craig Ulrich ${ }^{1}$, \\ Michelle Robertson ${ }^{1}$, Barry Freifeld ${ }^{1}$, Thomas Daley ${ }^{1}$, Inder Monga ${ }^{3}$, Chris Tracy ${ }^{3}$ \\ ${ }^{1}$ Energy Geoscience Division, Lawrence Berkeley National Laboratory \\ ${ }^{2}$ Earth and Planetary Science Department, University of California, Berkeley \\ ${ }^{3}$ Energy Sciences Network, Lawrence Berkeley National Laboratory \\ ${ }^{4}$ Formerly Lawrence Berkeley National Laboratory, now FEASIBLE Inc. \\ * Corresponding author: JBAjo-Franklin@Ibl.gov
}

\begin{abstract}
Several recent studies have demonstrated that Distributed Acoustic Sensing (DAS) can utilize existing subsurface telecom fiber (i.e. dark fiber) for high quality seismic measurements. Researchers to date have shown that this sensing combination, coupled to ambient noise interferometry techniques, can effectively image the shallow subsurface $(<30 \mathrm{~m})$ using vehicle and infrastructure noise $(f=8-30 \mathrm{~Hz})$. We present the first long-offset surface wave inversion study targeting deeper $(\sim 500 \mathrm{~m})$ structure using DAS and dark fiber. This study utilizes a previously acquired dataset collected on a $23 \mathrm{~km}$ fiber section between West Sacramento and Woodland, CA, part of the DOE Energy Science Network (ESnet). By targeting noise generated by a co-linear rail line, broadband and rich in low frequencies (down to $f=1 \mathrm{~Hz}$ ), and long array offsets, we generate high-quality interferometric gathers suitable for inversion. Subsequent surface wave inversions using a multimode Monte Carlo (MC) sampling algorithm are consistent with geology and available confirmatory datasets derived from co-located sonic logs. The relatively sparse confirmatory data demonstrates, by comparison, the utility of the high spatial sampling provided by DAS. These results open the door to larger regional DAS studies targeting deeper targets but with resolutions higher than those afforded by the use of persistent low frequency $(\mathrm{f}<1 \mathrm{~Hz})$ ocean microseism-related noise.
\end{abstract}

\section{Introduction}

The characterization of the top several hundred meters of the Earth's subsurface is crucial for understanding a variety of phenomena including near-surface property variations for geohazard evaluation or distribution and accessibility to water and other resources. However, our current understanding of the subsurface at these depths is limited by our ability to image its structure and temporal variations at high resolution using classical geophysical approaches. In seismological studies, specifically, the high cost of active surveys and long-term deployments and the sparse coverage of permanent arrays make it challenging to acquire high-resolution data at regional scale. These limitations result in missed information that can lead to restricted understanding of geological structures and unidentified hazards as well as limited capacity for process monitoring. 
Recently, the combination of novel sensing techniques with the use of already existing sensing networks has offered an attractive alternative to classical seismological studies. Here, we explore the applicability of Distributed Acoustic Sensing (DAS) using so-called "dark fiber" networks. These networks consist of subsurface fiber-optic cables that were originally deployed for telecommunication purposes but are currently not in use for data transmission. Because of the high cost of commercial fiber installation, it is common practice to install significantly more fiber than needed for current demand. This custom in combination with technological advances in available bandwidth per cable yields an excess of fiber that is not in use. These dark fiber networks are widespread, are found both onshore and offshore, and are often available for lease and purchase to be repurposed as sensing arrays. Recent studies have demonstrated the potential of combining DAS and dark fiber networks for near-surface imaging and earthquake seismology (Dou et al., 2017; Ajo-Franklin et al., 2019; Jousset et al., 2018).

Distributed Acoustic Sensing (DAS) is an innovative and rapidly developing technology that uses the principles of coherent optical time-domain reflectometry (COTDR) to make spatially distributed measurements of extensional strain or strain rate along an optical fiber (Parker et al., 2014; Hartog et al., 2017). A laser pulse sent down the fiber optic cable is backscattered by impurities in the fiber (Rayleigh scattering) and measured by an interferometric system. When extensional strain is applied at a location along the cable, the phase of the backscattered light changes. The system correlates these changes at specific locations along the cable to strain in the fiber at those positions. Differences in phase and amplitude of the backscattered light profile are measured over short subsets of the cable, referred to as gauge length. DAS technology enables acquisition of high-resolution seismological data at frequencies from the $\mathrm{kHz}$ to $\mathrm{mHz}$ for long distances (tens of $\mathrm{km}$ ) and at very dense spatial samplings (down to $1 \mathrm{~m}$ ) in contexts in which the use of conventional sensors is intricate and/or costly (Daley et al., 2016; Becker et al., 2017). DAS is incrementally being adopted in the field of applied geophysics and a variety of studies have demonstrated its suitability for a range of applications such as vertical seismic profiling (Daley et al., 2013; Mateeva et al., 2013; Wu et al., 2015; Wu et al., 2017), time-lapse monitoring of near-surface properties (Dou et al., 2017; Ajo-Franklin et al., 2019), earthquake detection (Lindsey et al., 2017; AjoFranklin et al., 2019; Li \& Zhan, 2018), and hydrological monitoring (Becker et al., 2017).

In this study, we investigate the potential of combining DAS and dark fiber networks for ambient noise imaging at intermediate depths. In the past decade, many studies have shown that ubiquitous vibrations generated by natural and anthropogenic sources (e.g. wind, rivers, ocean waves, traffic) can be analyzed to recover subsurface information. By cross-correlating ambient seismic noise recordings at two receivers, subsurface velocity structure between the two can be retrieved using interferometric approaches (Bensen et al, 2007, Snieder \& Larose, 2013; Campillo \& Roux, 2015). Because most of the noise has its origin on the surface, most of the observed ambient seismic noise has a strong component of surface waves that are exploited for a variety of imaging purposes (Campillo \& Roux, 2015). A large number of ambient seismic noise studies utilize broadband sensors located tens of kilometers apart for subsurface imaging at the crustal or lithospheric scale (Li et al., 2010; Molinari et al., 2015; Shapiro et al., 2005; Yang et al., 2008). These works generally exploit natural ambient seismic noise in the microseisms band ( $5 \mathrm{~s}$ and above) to reach depths of tens of kilometers or greater with resolution of several tens of kilometers. In near-surface and geotechnical applications, classical methods such as multichannel analysis of surface waves (MASW) exploit noise at high frequencies (typically $10 \mathrm{~Hz}$ or greater) to image the Vs structure of the top $30 \mathrm{~m}$ of the subsurface (Park et al., 1999; Kaufmann et al., 2005; E. H. Parker \& Hawman, 2012; Xia, 2014). These studies commonly use short arrays of densely spaced short-period sensors (e.g. geophones). These arrays 
provide velocity information with vertical resolution in the order of a few meters, but their lateral extent and spatial coverage is limited. These constraints restrict its application to local structures. The opposite is true for studies of the top hundreds of meters of the Earth's subsurface. Whereas spatial coverage and deep penetration can be achieved with extensive, broadband arrays, dense spacing is not feasible with conventional sensors due their high cost, which results in poor lateral resolution.

In this context, DAS is an excellent alternative to bridge the gap between low-frequency, regional studies and high-resolution, local investigations. DAS allows deployments of seismic arrays capable of recording broadband data at high spatial resolution for distances of several km. Telecom fiber-optic networks, in turn, are commonly routed along road and railway right-of-ways, areas which are rich in ambient noise. In a previous study, we demonstrated that ambient noise interferometry could be applied to DAS ambient noise recordings generated by a train travelling parallel to a section of a dark fiber network (Ajo-Franklin et al., 2019). In this work, ambient noise analysis at frequencies in the traffic band were used to image the top $50 \mathrm{~m}$ of the subsurface and to monitor groundwater level variations. To date, only a few other studies have successfully used train-generated noise for imaging purposes (Nakata et al., 2011; Quiros et al., 2016). In their study, Quiros et al. (2016) show that the ambient field generated by trains can be utilized to produce virtual records of surface and body waves that can be analyzed for subsurface imaging down to $\sim 200 \mathrm{~m}$. A recent study by Inbal et al. (2018) demonstrates that noise generated by freight trains can be recorded in borehole arrays at distances of up to $50 \mathrm{~km}$ from the railway, and it is used to estimate average attenuation values for depths between 200 and $500 \mathrm{~m}$.

In this study, we use the DAS dataset introduced in Ajo-Franklin et al. (2019) to explore the potential of exploiting train-generated noise recorded by a dark fiber network for imaging the subsurface down to 500 $\mathrm{m}$ and compare the results to exploration sonic well logs available along the profile. We find that the inverted Vs profiles are consistent with available data and are well-constrained for the upper $300 \mathrm{~m}$ with higher uncertainty in lower units due to the limited coherent energy generated by the train below $0.5 \mathrm{~Hz}$.

\section{Dark Fiber networks: the ESnet Dark Fiber Testbed}

The dataset analyzed in this study was acquired using the fiber optic cable installation maintained as part of the Energy Sciences Network's (ESnet) Dark Fiber Testbed. ESnet is a nationwide US Department of Energy Office (DOE) user facility. It provides high-performance, unclassified infrastructure that connects DOE research sites (including supercomputer facilities and major scientific instruments) as well as research and commercial networks. The Dark Fiber Testbed itself consists of a 20,920 km (13,000 miles) network of short and long haul telecommunication fiber used for network communication research. This network utilizes single mode telecommunication fiber optic cables of varying age and installation modes, none installed with sensing in mind, making it a representative example of currently available commercial networks and expected DAS data quality. 


\section{Study site and data acquisition}

The study site under investigation is located on the Sacramento River flood plain, northwest of the city of Sacramento, California (Figure 1). It is located within the southern portion of the Sacramento Valley, which in turn constitutes the northern arm of California's Central Valley. The shallow stratigraphy of the site mainly consists of Quaternary flood plain deposits comprised of an intercalation of clays, silts, fine sands and gravels that can reach thicknesses of up to $46 \mathrm{~m}$ in the area. Regionally, these young sediments are underlain by alluvial deposits of Pliocene age, that are composed of loose to moderately compacted clays, silts, sand and gravels, and by the partially lithified deposits of the Tehama formation, which includes silts, clays and fine sands that enclose sand and silt, gravel and silt and cemented conglomerate lenses (Olmsted \& Davis, 1961). Deeper horizons include fill sediments in the Markley Gorge (600-800 mbgs, see PepperKittredge \& Wilson, 1984) which overly the late Cretaceous Mokelumne River Formation ( 800-1000 mbgs), the latter of which produces gas at commercial quantities. The study site is in close proximity to the Conway Ranch gas field (Campion Jr, 1980) as well as the Todhunter Lake field (Hunter et al., 1984); as a result, numerous wells have been drilled along the transect, all with available logs.

Within this region, data was acquired along a $23.29 \mathrm{~km}$ long transect of the ESnet's Dark Fiber Testbed that runs between West Sacramento and the town of Woodland in Yolo County (Figure 1). This section of the network extends from urban areas in West Sacramento into farmland close to the Sacramento river, crossing Interstate 5 before bending westwards towards Woodland. For most of its length, the network runs along a rail line and a local road.

This study builds on the work presented in Ajo-Franklin et al. (2019), which uses the same dataset for imaging near-surface structure, monitoring groundwater table variations, and detecting teleseismic earthquakes. Data was acquired using a single DAS interrogator between July 28th, 2017 and January 18th, 2018. The DAS interrogation unit (Silixa iDAS, Elstree, UK) was installed on a vibration isolated table inside a telecommunication Point-of-Present (PoP) facility in West Sacramento. The authors refer to AjoFranklin et al. (2019) for more details on hardware and installation conditions. Ambient noise was recorded at a sampling rate of $500 \mathrm{~Hz}(2 \mathrm{~ms})$, with spatial sampling of $2 \mathrm{~m}$ and a gauge length of $10 \mathrm{~m}$. Data was continuously recorded and stored in the form of 1-minute files in 8 TB external hard drives that were manually exchanged weekly during the duration of the experiment.

Mapping of linear distances along the fiber cable and actual location coordinates was established by carrying out impact tests at surface locations and identifying their response along the cable. These points were surveyed with a high accuracy differential GPS and associated with the corresponding distance along the fiber. Linear interpolation was performed between the known points. As a result, the uncertainty associated to the final subsurface geometry of the cable is in the order of $5 \mathrm{~m}$ (Ajo-Franklin et al., 2019). 


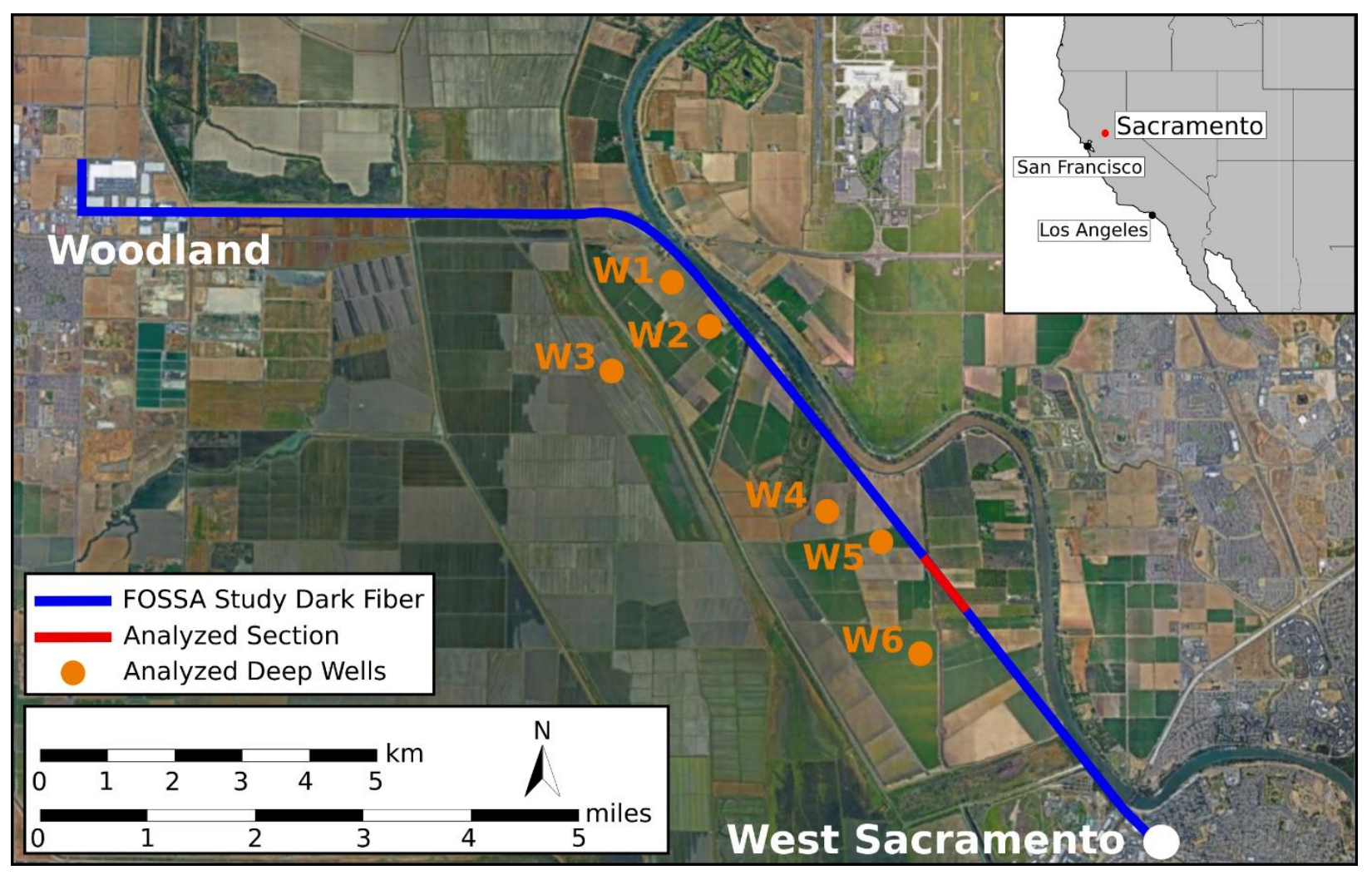

Figure 1. Aerial photograph showing location of the study site and transect of the ESnet Dark Fiber Testbed used in this study. Labelled orange circles are deep boreholes with sonic log information used for groundtruth of ambient noise analysis results. W1 = Hanks 3-4; W2 = Unit 1-1; W3 = Conway 4-2; W4 = Rivercat 11-2; W5 = Mattos 1; W6 = Agriventure Ensher (AE) 19-1.

\section{Data characteristics and analysis of noise sources}

Following the establishment of the correct geometry, the characteristics of the ambient noise signals recorded by the DAS array were then analyzed. Due to its location straddling an urban area and farm land and its proximity to major infrastructure, this network is an excellent natural laboratory to test the applicability of DAS using dark fiber networks for recording seismic noise from different sources.

Figure 2a shows a 10 second recording of ambient seismic noise across the entire fiber optic cable, starting in West Sacramento and finishing near Woodland. The most evident feature is the deterioration in data quality along the array at significant distances from the recording unit. Clear infrastructure-related seismic signals are observed for the first $16 \mathrm{~km}$ of the profile, where the data is relatively clean and has sufficient signal-to-noise ratio to observe discrete signals. Beyond that location, the signal slowly degrades and is dominated by optical noise at the distal end of the profile. Several localized noisy sections are also observed towards the beginning of the profile. Within the first $0.5 \mathrm{~km}$ of the profile, data is affected by noise inside the Point-of-Presence where the recording unit sits. At a distance of about 3.5 to $4 \mathrm{~km}$, data quality is affected by poor coupling of the fiber optic cable, which is attached to a bridge in this section. After this evaluation, noisy sections were disregarded for further analysis. 
Besides data quality variability, differences in the character of the recorded ambient noise signals are also observable. Most of the energy recorded corresponds to traffic noise along local roads and along regional highways located to the north of the study site, as well as diffuse urban noise originated in Sacramento. The signal with the highest amplitude corresponds to noise generated by a train travelling along the railway that runs parallel to the fiber optic line. In Figure $2 b$, the frequency content of the corresponding 1 minute of data is analyzed as a function of distance along the cable. As is to be expected, the trafficgenerated noise dominates the spectrum and is concentrated within a frequency band between 3 and $30 \mathrm{~Hz}$. Noise associated with railroad activity, however, is characterized by a broadband signal that varies as the train is approaching and departing a particular location along the cable. Differences in the frequency spectrum of the distinct noise signals are more evident in Figure 3, where normalized spectral amplitudes of the three main type of noise signals identified in the data are shown. The background noise spectra shown in blue in Figure 3a corresponds to the frequency content of a 1 minute file recorded during night time, when traffic noise is minimal. These data have the smallest amplitude at all frequencies, and its spectrum is characterized by an increasing trend towards high frequencies. A small peak is observed at a frequency of approximately $4 \mathrm{~Hz}$ which most likely corresponds to urban noise from nearby Sacramento. As expected, car-generated noise has higher amplitudes than background noise, and most of its energy is concentrated at frequencies between 3 and $20 \mathrm{~Hz}$, with the highest peak being at $4 \mathrm{~Hz}$ (green curve in Figure 3a). In comparison with these two types of noise sources, energy generated by the train is characterized by much higher amplitudes at all frequencies. Even though most of the energy is concentrated in the traffic-band, with a prominent peak at about $8 \mathrm{~Hz}$, the spectral content at lower frequencies (i.e. below $3 \mathrm{~Hz}$ ) is significantly higher. This characteristic frequency spectrum makes traingenerated noise the most energetic and most broadband signal present in our study area, and hence the most appropriate ambient seismic noise for the purposes of intermediate-to-large scale imaging of the subsurface.

A more quantitative analysis of the depth penetration of train-generated noise in our site can be obtained by calculating sensitivity curves at the different frequencies contained in our ambient noise recordings. Figure $3 \mathrm{~b}$ illustrates the vertical and horizontal components of displacement for the fundamental mode of a synthetic Rayleigh wave as a function of depth and frequency for a 6-layer subsurface model with increasing velocity. These curves show that sensitivity rapidly decreases with depth for both components of displacement, especially for high frequencies ( $>3 \mathrm{~Hz}$ ). This decay is more acute for the horizontal component of displacement (dashed lines in Figure $3 \mathrm{~b}$ ). For this velocity structure, maximum sensitivity is obtained for depths between $50 \mathrm{~m}$ and a $100 \mathrm{~m}$. Significant sensitivity is achieved at depths down to $\sim 300 \mathrm{~m}$ for waves with a frequency of $1 \mathrm{~Hz}$, but frequencies as low as $0.5 \mathrm{~Hz}$ are needed in order for Rayleigh wave energy to be sufficiently excited at the deepest sections of the profile. Hence, train noise is best suited for deeper imaging. 

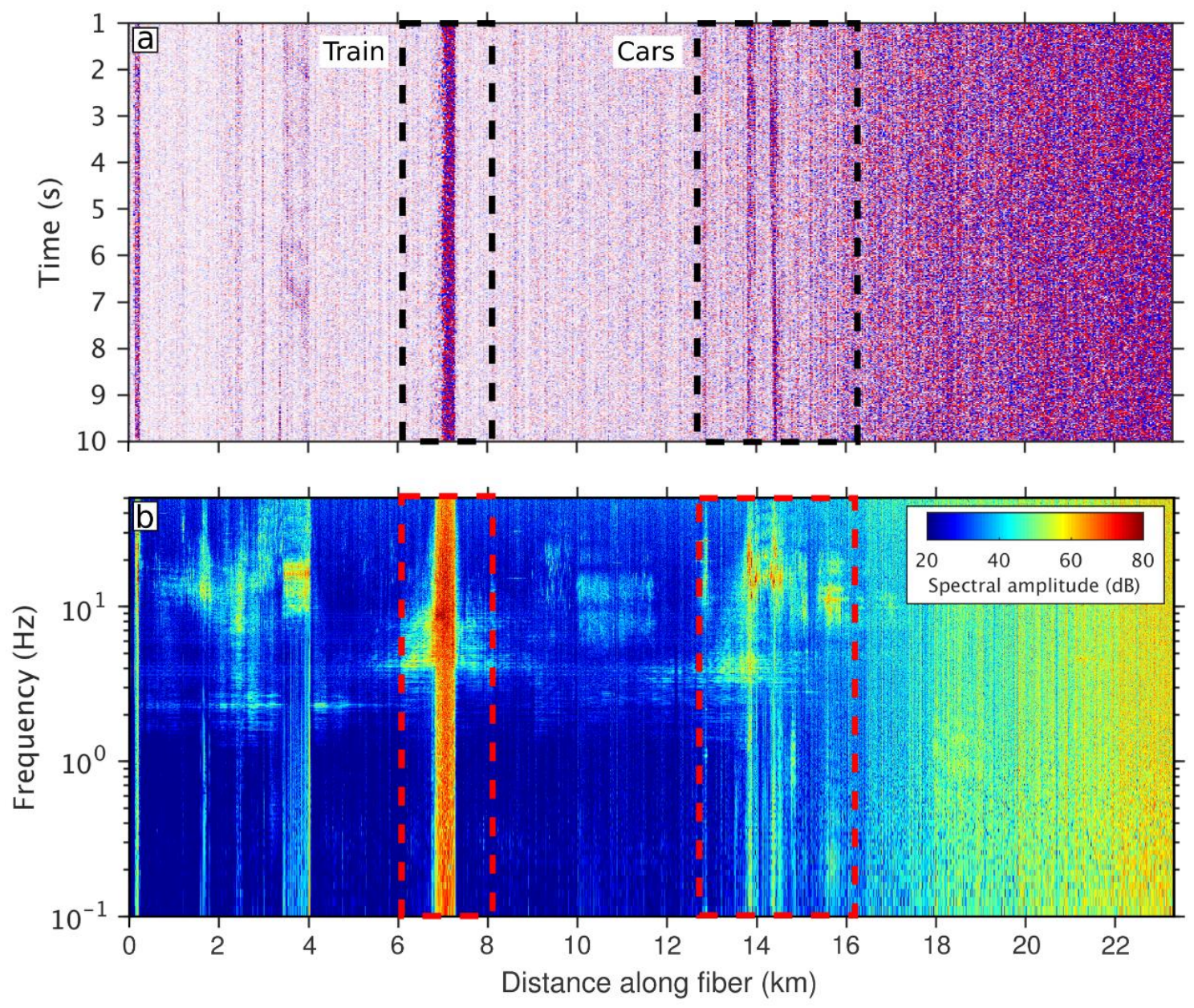

Figure 2. Data characteristics along the dark fiber array. (a) 10 seconds-record of raw ambient seismic noise data. Traffic noise generated by a freight train running on-line with the array and cars travelling along a road nearby are the most conspicuous signals. (b) Frequency content variation across the array. Red, dashed-line rectangles correspond to sections containing train and car noise indicated in (a). 

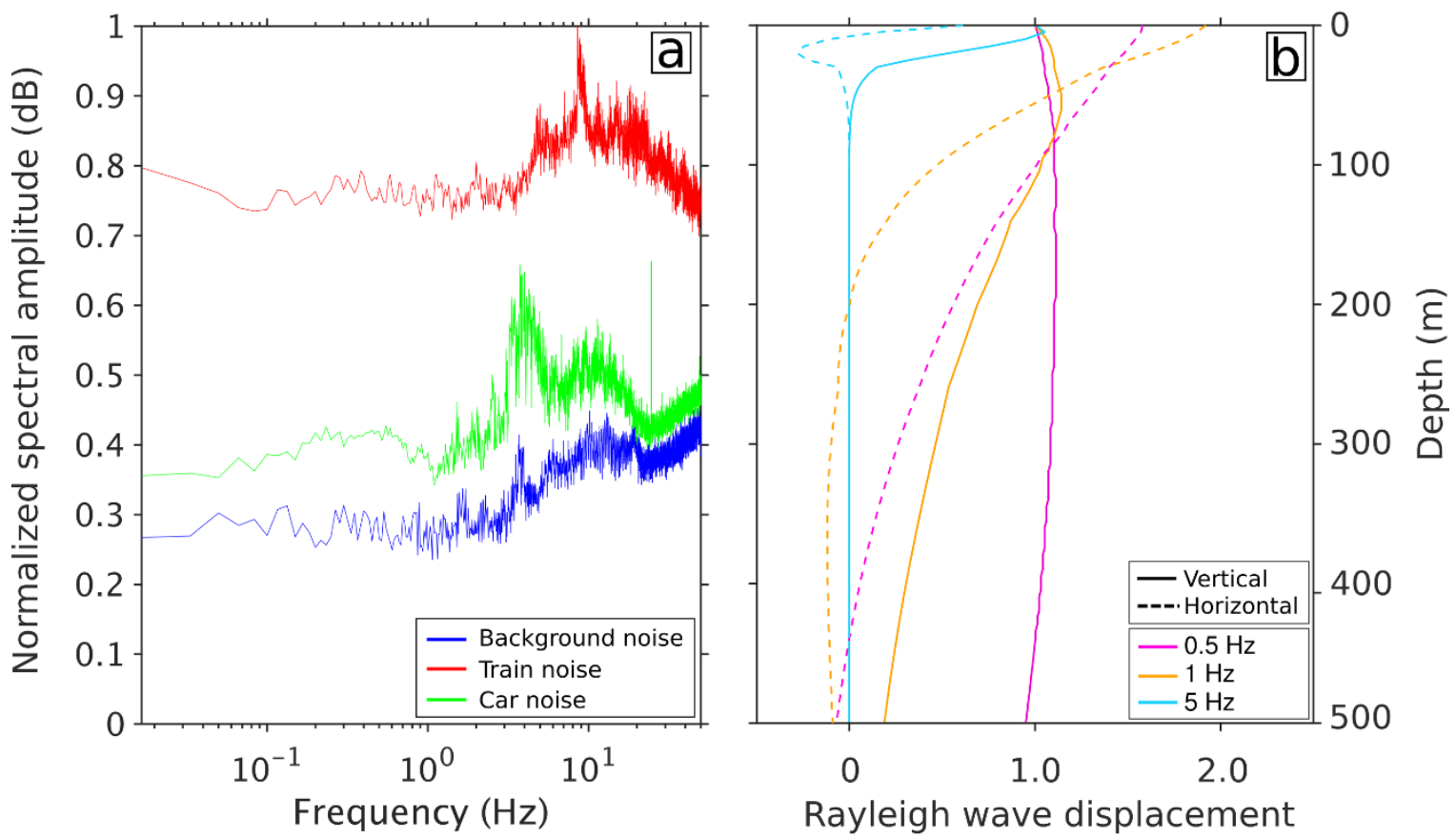

Figure 3. (a) Comparison of spectral amplitude of the distinct noise signals sensed in our study site for a 1 minute of seismic noise recording. Blue = background noise recorded at night, where traffic noise was minimal; green = noise generated by moving cars; red = noise generated by an approaching train. (b) Sensitivity kernels represented by the displacement of the vertical and horizontal components of a synthetic Rayleigh wave as a function of depth for distinct frequencies contained in the train-generated noise used for ambient noise analysis, calculated for a simple 6 -layer Vs model. For the horizontal component of displacement, positive values indicate prograde motions, whereas negative values indicate retrograde motions.

\section{Processing strategy}

Based on the previous analysis, an approach similar to that used in Ajo-Franklin et al. (2019) is used in this study. Infrastructure noise generated by a freight train running along the dark fiber cable is exploited to retrieve the shear-wave velocity structure of the topmost few hundred meters beneath the cable. The complete processing workflow is illustrated in Figure 4, which starts with the acquired 1-minute noise records and ends with 1-dimensional shear-wave velocity profiles. This processing framework is very similar to that of Ajo-Franklin et al. (2019), slightly modified to achieve deeper imaging, and is based on well-established ambient noise analysis procedures (e.g. Bensen et al., 2007). A key difference with the processing sequence used in Ajo-Franklin et al. (2019) is that 30 minute-long records instead of 1 minutelong records are processed. 


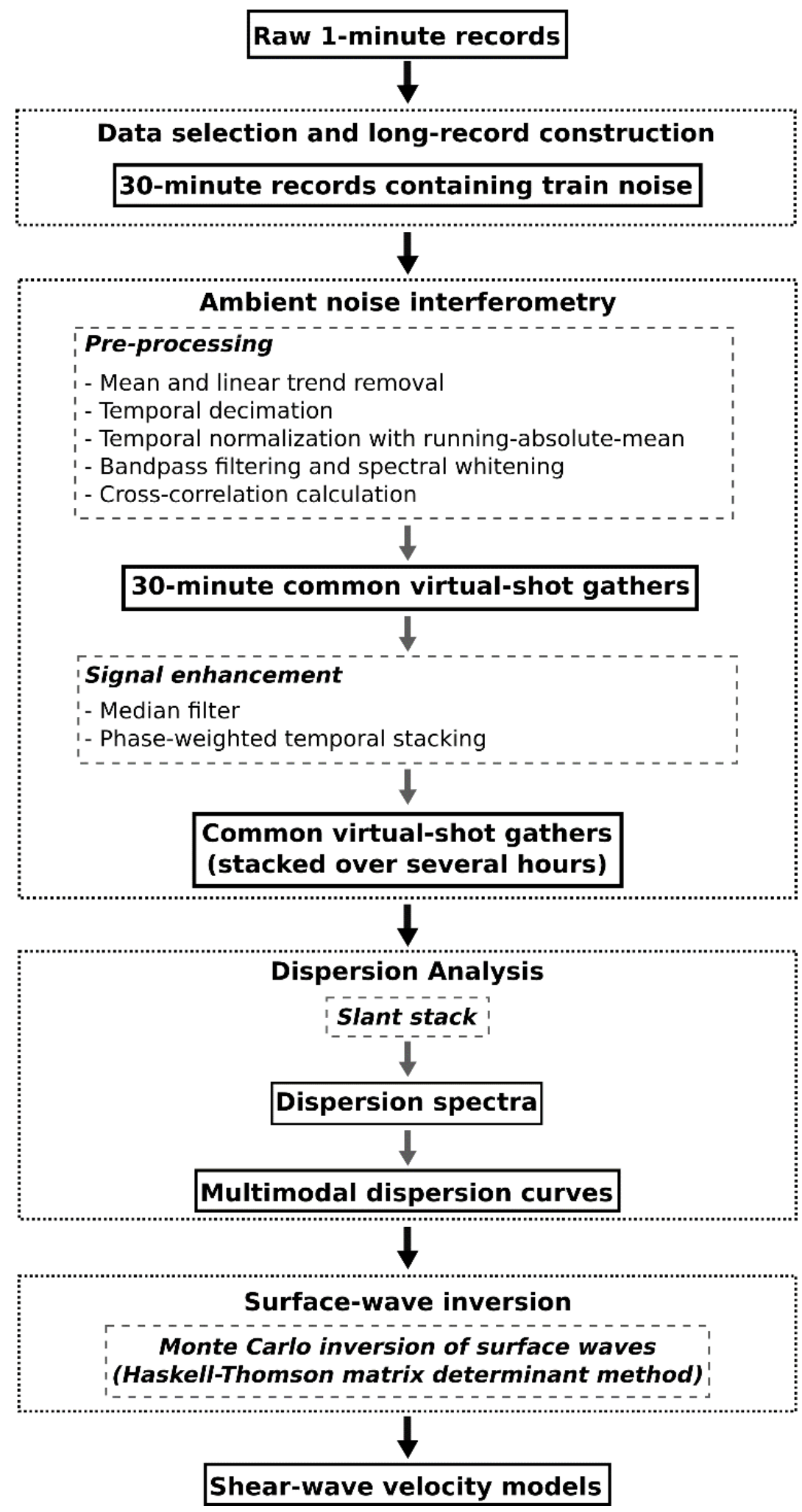

Figure 4. Ambient noise processing flow for Vs recovery at intermediate depths. 


\section{Data selection}

The analysis is performed on $1 \mathrm{~km}$ long segments of the array. These sections allow retrieving surfacewave energy at long offsets, which is necessary for large-scale imaging using long wavelengths, but still are assumed to be adequate for 1-dimensional analysis of subsurface structure. In order to obtain sampling of deep structure and surface-wave energy retrieval at long distances, it is important that enough low frequency energy is captured. With this objective, the acquired noise data are organized into 30-minute long records to ensure that low frequency (i.e. long wavelength) phases are included (e.g. Seats et al., 2012).

As shown in Figure 3a, train energy is the most energetic and broadband source available in our study site. Accordingly, the data selected for analysis consists exclusively of records containing energy created by an approaching or departing train. For each $1 \mathrm{~km}$ long section, 1-minute records containing train energy are identified by scanning trace windowed root-mean-square (RMS) amplitude on the raw data and are tagged as "train pass" (Ajo-Franklin et al., 2019). Next, 1-minute files acquired between 31 and 1 minutes before or after the "train passes" in our selected cable section are concatenated into the 30-minute long records to which ambient noise interferometry is subsequently applied.

\section{Ambient noise interferometry and dispersion analysis}

After construction of these longer records, pre-processing of the raw data is needed in order to prepare them for cross-correlation (Bensen et al., 2007; Dou et al., 2017). Static offsets and linear trends are removed from the raw, 30-minute long noise records, followed by temporal decimation down to a sampling rate of $8 \mathrm{~ms}(\mathrm{f}=125 \mathrm{~Hz})$. Temporal normalization is applied using a running absolute-mean procedure with a running window of $0.5 \mathrm{~s}$, in order to reduce the effect of undesired signals such as earthquakes. Next, the data are bandpassed between 0.002 and $15 \mathrm{~Hz}$ and these frequencies balanced using spectral whitening. Following these preparation steps, for each of the 30-minute long records, the southernmost receiver of the $1 \mathrm{~km}$-long section is treated as the virtual source and cross-correlated with all other receivers in that section to construct common virtual-source gathers. As observed in Figure $5 a$ and $5 c$, the resultant gathers are contaminated by horizontal (infinite velocity) noise that affects all channels and is especially strong at zero lag time. This noise is most likely the effect of cross-correlating coherent optical noise generated by the iDAS unit. This noise is suppressed by calculating the median amplitude of each trace in the gather and subtracting it. Further signal enhancement and signal-to-noise ratio improvement is achieved by temporally stacking multiple 30-minute long records, which suppresses incoherent signals. The phase-weighted stacking method of Schimmel \& Paulssen (1997) is used, which allows data quality improvement with fewer records than what would be needed if a mean stack was performed. Here, 45 records are stacked, corresponding to 22.5 hours of train noise (Figure $5 b$ and $5 d$ ).

Ambient noise interferometry is followed by dispersion analysis. Slant stacking is applied to the common virtual-shot gathers to transform the data from the time-distance domain to the frequency-velocity (dispersion) domain. Once the dispersion spectrum is calculated, multimodal dispersion curves are manually extracted and used as input for a multimodal surface-wave inversion. 

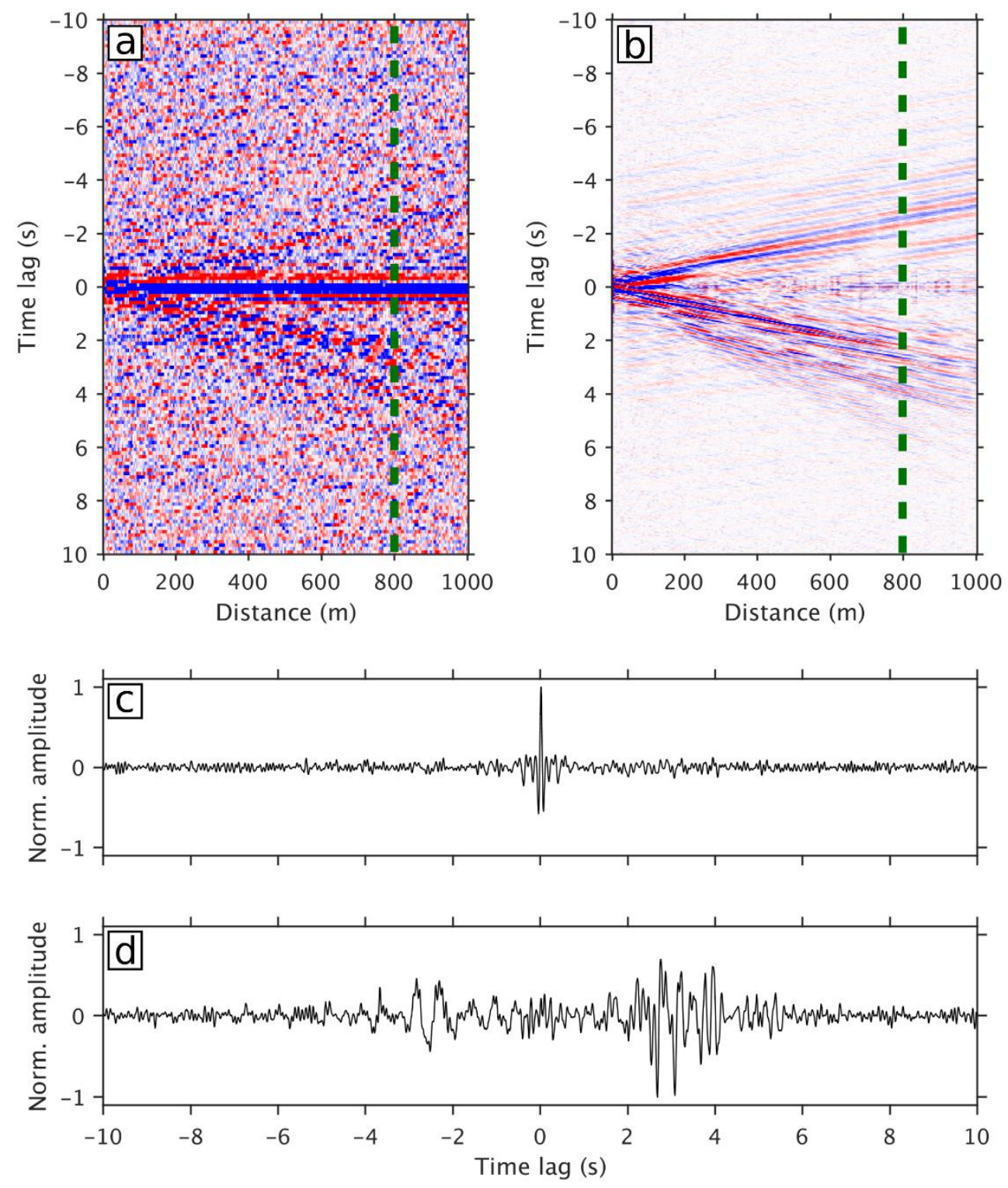

Figure 5. Comparison between 30-minute single virtual shot gather and phase-weighted stack of 42 virtual shot gathers. (a) Time- distance display of single cross-correlation. Green dashed-line indicates trace shown in (c). (b) as in (a) for phase-weighted stack. (c) Normalized amplitude - time lag close up view of a single trace at offset indicated in (a). Note signal is dominated by horizontal noise at 0 s time lag. (d) Same as (c) for a trace in virtual stack shown in (b). Note the high amplitude group arrival between -2 and $-3 \mathrm{~s}$ and between 2 and $4 \mathrm{~s}$.

\section{Multimodal Inversion Using the Haskell-Thomson Determinant Method}

As discussed in Dou et al. (2017) and Ajo-Franklin et al. (2019), mode-numbering can be difficult in DAS datasets. Consequently, we adopt the inversion approach developed by Maraschini et al. (2010), which does not require explicit mode numbering. As opposed to minimizing the misfit between observed and calculated dispersion curves, this inversion algorithm minimizes the determinant of the model-predicted 
Haskell-Thomson propagator matrix. This matrix describes the propagating media and its determinant depends on model parameters such as $\mathrm{Vs}, \mathrm{Vp}$ (or Vp/Vs ratio), density and thickness of each model layer, as well as the frequency-velocity point at which the determinant is calculated. The algorithm evaluates the determinant misfit function at the frequency-velocity pairs of our observed dispersion curves and finds the model that minimizes the function at these data appoints using the L1 norm. Details on the calculation of the determinant misfit function and the inversion algorithm are found in Maraschini et al. (2010) and Maraschini \& Foti (2010).

A Monte Carlo sampling approach is adopted to allow for a sparse parameterization of the model space Maraschini \& Foti, 2010). The model is constructed as a series of distinct layers over a half space. Thorough parameter testing suggests that a 6 -layer model ( 5 layers plus the half-space) is most adequate to describe the subsurface below the selected cable section. Vs and layer thickness are inverted for. For each Monte Carlo run, a pool size of $1 \times 106$ models is defined and specified search bounds are broad, allowing model exploration. Search bounds for each model parameter are specified in Table 1. After inversion, all models are ranked by their $\mathrm{L} 1$ norm misfit and the top $0.1 \%$ best-fitting models are selected for analysis and interpretation. The Haskell-Thomson determinant method provides the advantage of multimodal, nonlabeled data to be used as inversion input. However, it is important to note that this approach comes with the pitfall that several local minima are present in the misfit function. In some cases, this feature will make the resultant velocity inversion highly dependent on the choice of model bounds, since there is the risk of the inversion to converge into a local minimum.

Table 1. Upper and lower bounds of Monte Carlo sampling for inversion parameters.

\begin{tabular}{|l|l|l|l|l|}
\hline Model Layer & $\begin{array}{l}\mathbf{V}_{\mathbf{s}} \text { lower bound } \\
(\mathbf{m} / \mathbf{s})\end{array}$ & $\begin{array}{l}\mathbf{V}_{\mathbf{s}} \text { upper bound } \\
(\mathbf{m} / \mathbf{s})\end{array}$ & $\begin{array}{l}\text { Thickness lower } \\
\text { bound }(\mathbf{m})\end{array}$ & $\begin{array}{l}\text { Thickness upper } \\
\text { bound }(\mathbf{m})\end{array}$ \\
\hline 1 & 250 & 700 & 10 & 60 \\
\hline 2 & 300 & 900 & 30 & 100 \\
\hline 3 & 400 & 1000 & 30 & 100 \\
\hline 4 & 600 & 1200 & 50 & 100 \\
\hline 5 & 900 & 1600 & 50 & 100 \\
\hline 6 (half space) & 1000 & 2000 & - & - \\
\hline
\end{tabular}

\section{Results}

\section{Site Comparison Data}

To assist in evaluating the inversion results, we made use of a large number of archival sonic logs acquired in gas wells drilled near the fiber profile. Well logs were obtained from the California Department of Oil, Gas, \& Geothermal Resources (DOGGR) on-line database, picked, and digitized to LAS format. Sonic logs dated from the 1960 s to early 2000 s and their quality was highly variable. In all cases, only P-wave sonic logs were available, necessitating development of $\mathrm{V}_{\mathrm{p}} / \mathrm{V}_{\mathrm{s}}$ model for direct comparison to our $\mathrm{Vs}$ inversion profiles. Additionally, no wells were logged to surface so our available constraints extend only from $\sim 180 \mathrm{~m}$ depth to the extent of our inversion profile. Well locations and corresponding API identification 
numbers are detailed in Table 2. The relatively sparse distribution of well data (despite the area's history of natural gas exploration) highlights the potential of dark fiber DAS to provide subsurface information with high spatial sampling.

Table 2. Location and API identification numbers of well logs from the DOGGR database, used in this study to evaluate inversion results.

\begin{tabular}{|l|l|l|l|}
\hline Well name & Longitude & Latitude & API number \\
\hline Hanks 3-4 & -121.62443 & 38.669974 & 11320756 \\
\hline Unit 1-1 & -121.61713 & 38.662796 & 11320931 \\
\hline Conway 4-2 & -121.637443 & 38.655187 & 11321126 \\
\hline Rivercat 11-2 & -121.600432 & 38.636183 & 11321189 \\
\hline Mattos 1 & -121.588339 & 38.633324 & 11320751 \\
\hline Agriventure Ensher (AE) 19-1 & -121.581496 & 38.617168 & 11321099 \\
\hline
\end{tabular}

Figure $6 \mathrm{~A}$ shows the catalog of log data used in developing our comparison model. The colored dots represent $V_{p}$ measurements for the 6 wells considered. As can be seen, while structural variations exist between the wells, as would be expected given the different log vintages and departures from 1D geologic structure, the first $600 \mathrm{~m}$ lacks any units with distinct P-wave properties. This zone appears to have a consistent depth gradient, likely driven by increasing overburden stress given the relatively young age of the sediments and known absence of cementation at these depths. Based on this observation, we decided to average the logs to develop a larger scale 1D model; in Figure 6A, this is shown as the bold black line.

To convert this mean $\log V_{p}$ profile to a $V s$ model, we explored a variety of empirical as well as analytic models to generate an appropriate $V_{p} / V_{s}$ ratio. Our first attempts made use of classical empirical models such as the regression set proposed by Brocher (2008) for Northern California. The depth regressions in Brocher yielded higher P-wave velocities than observed in our log database suggesting they are not well suited for this site.

Based on the observed depth trend, we evaluated the use of several contact-theory based models to develop an appropriate $V_{p} / V_{s}$ ratio model. Following the summary available in Mavko et al. (1998), we tested the Hertz-Mindlin (HM) and Walton Smooth (WS) models (Mindlin, 1949; Walton, 1987) for both predicting the observed $\mathrm{P}$-wave trend and for $\mathrm{V}_{\mathrm{p}} / \mathrm{V}_{\mathrm{s}}$ ratio estimation. We used these two contact theory models assuming a lithostatic stress trend of $0.022 \mathrm{MPa} / \mathrm{m}$ (equivalent to $1 \mathrm{psi} / \mathrm{ft}$ ) and a standard hydrostatic pore pressure trend. We assumed a constant porosity of 0.34 , an empirical porosity/coordination number conversion, and that the grain properties are that of pure quartz. After dry frame properties were calculated, we estimated water-saturated properties using Gassmann fluid substitution (Mavko et al., 1998). A volumetric average was used to calculate density. Figure 6B compares the resulting $\mathrm{HM}$ and WS predictions to the modeled P-wave velocity trend. The WS model with these assumptions appears to capture the trend effectively, although slightly overestimates velocity, likely due to the many simplifying assumptions.

$A V_{p} / V_{s}$ ratio based on the WS model was then used to convert the P-wave sonic logs to $V_{s}$ estimates. Figure $6 \mathrm{C}$ shows the converted sonic logs (black) with the analytical HM and WS predictions; the close correspondence between the analytical WS model and converted log estimates suggests that this 
approach is reasonable. This correspondence also justified utilization of the WS model for prediction of the shallower shear velocity structure; Figure 6D shows the integrated $V_{s}$ model used for our inversion comparisons consisting of the log conversion below $\sim 150 \mathrm{~m}$ and the WS estimation at shallower depths.
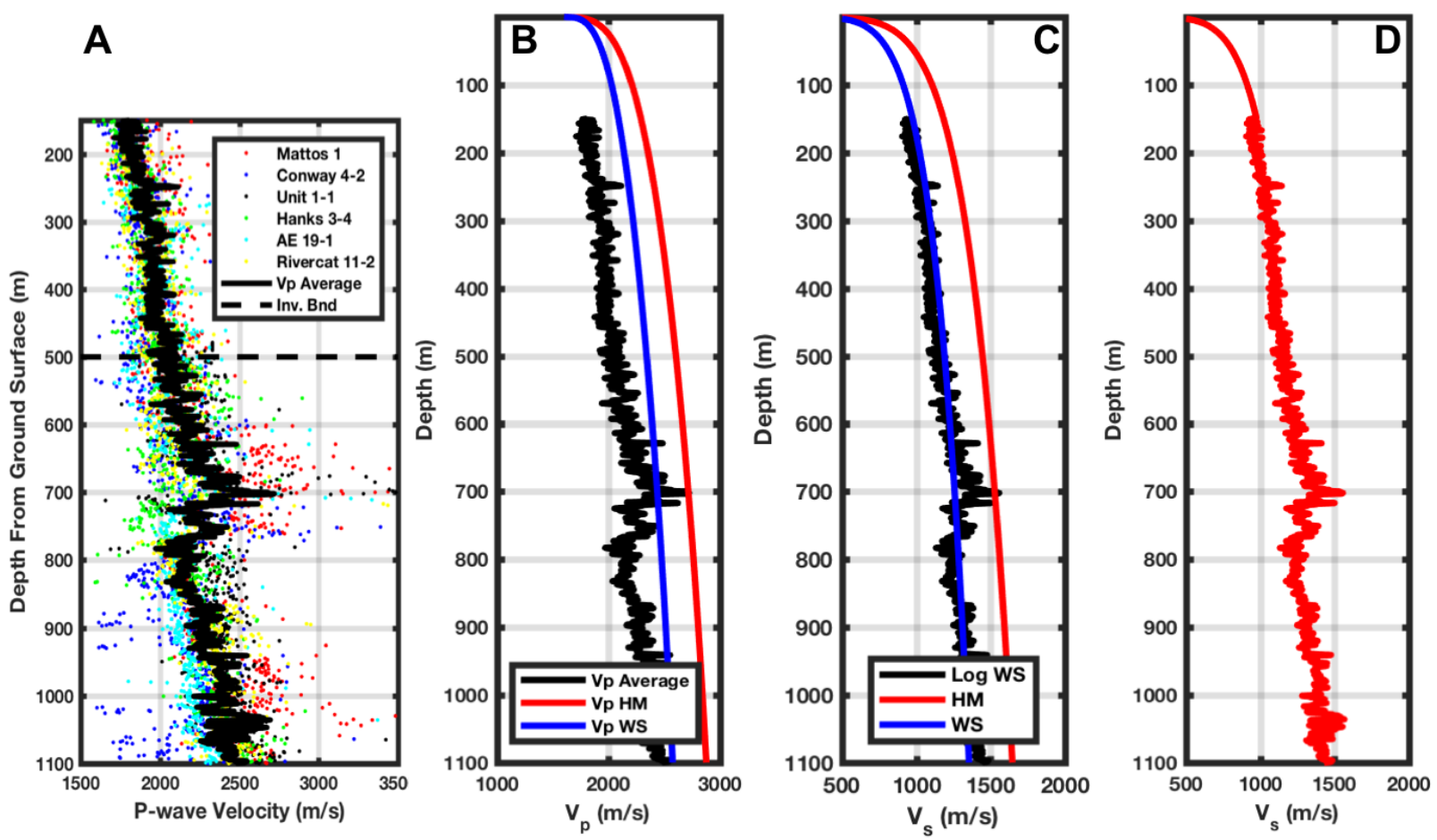

Figure 6. Datasets and development of a reference Vs(z) model; Panel A shows available sonic logs (colored dots) near the DAS profile as well as a $V_{p}$ depth average (black line). Panel B shows a comparison of the mean $V p$ log to two analytical contact theory models (Hertz-Mindlin, HM, and Walton Smooth, WS, models). Panel C shows the mean sonic log (black) converted to $V_{s}$ using a depth-dependent $V_{p} / V_{s}$ model derived from the Walton Smooth model. Panel $D$ shows the final reference $V_{s}(z)$ model consisting of the converted logs below $150 \mathrm{~m}$ and the Walton Smooth model above.

\section{Inverted Vs structure and comparison to groundtruth data}

Here, we present the results of applying the described processing approach to a $1 \mathrm{~km}$ long section located towards the southern end of the line (red line in Figure 1). Figure 7 shows the results of the dispersion analysis and the associated best-fit $\mathrm{V}_{\mathrm{s}}$ model obtained from the inversion. The inverted profile reveals an increasing velocity gradient within the top $250 \mathrm{~m}$, with no significant velocity variations (Figure 7c). The interfaces that characterize the model are most likely due to the nature of the inversion process, which does not allow modeling of velocity gradients but discrete layers only. Shear-wave velocities increase from about $250 \mathrm{~m} / \mathrm{s}$ at shallow depths to $\sim 1000 \mathrm{~m} / \mathrm{s}$ at a depth of $260 \mathrm{~m}$. Velocities remain the same down to $500 \mathrm{~m}$, which is the maximum depth of our model. Synthetic dispersion curves are calculated using the inverted model and can be seen to agree well with our dispersion observations (Figure 7a and 7b). 
Model uncertainty can be evaluated by examining the results of the top $0.1 \%$ best-fit $V_{s}$ profiles. To do that, we have divided the model parameter space into bins of $5 \mathrm{~m}$ depth by $25 \mathrm{~m} / \mathrm{s} \mathrm{V}_{\mathrm{s}}$ and have calculated how many models fall within these bins and taken the spread of these results as uncertainty bounds. As illustrated in Figure 7c, uncertainty increases with depth. As expected, lowest uncertainty is achieved for depths down to $\sim 100 \mathrm{~m}$, with slightly higher uncertainties for depths between $100 \mathrm{~m}$ and $\sim 250 \mathrm{~m}$. Higher model variability is observed at deeper depths, where uncertainty in $V_{s}$ is mostly within $500 \mathrm{~m} / \mathrm{s}$. These results are expected, since the low frequency content shown in our frequency-velocity spectra show low amplitudes below $\sim 1 \mathrm{~Hz}$ (Figure 7a and 7b). Stacking of longer ambient noise recordings in combination with spatial stacking of a few contiguous channels would potentially help recover more energy at the lowfrequency end of the spectra.
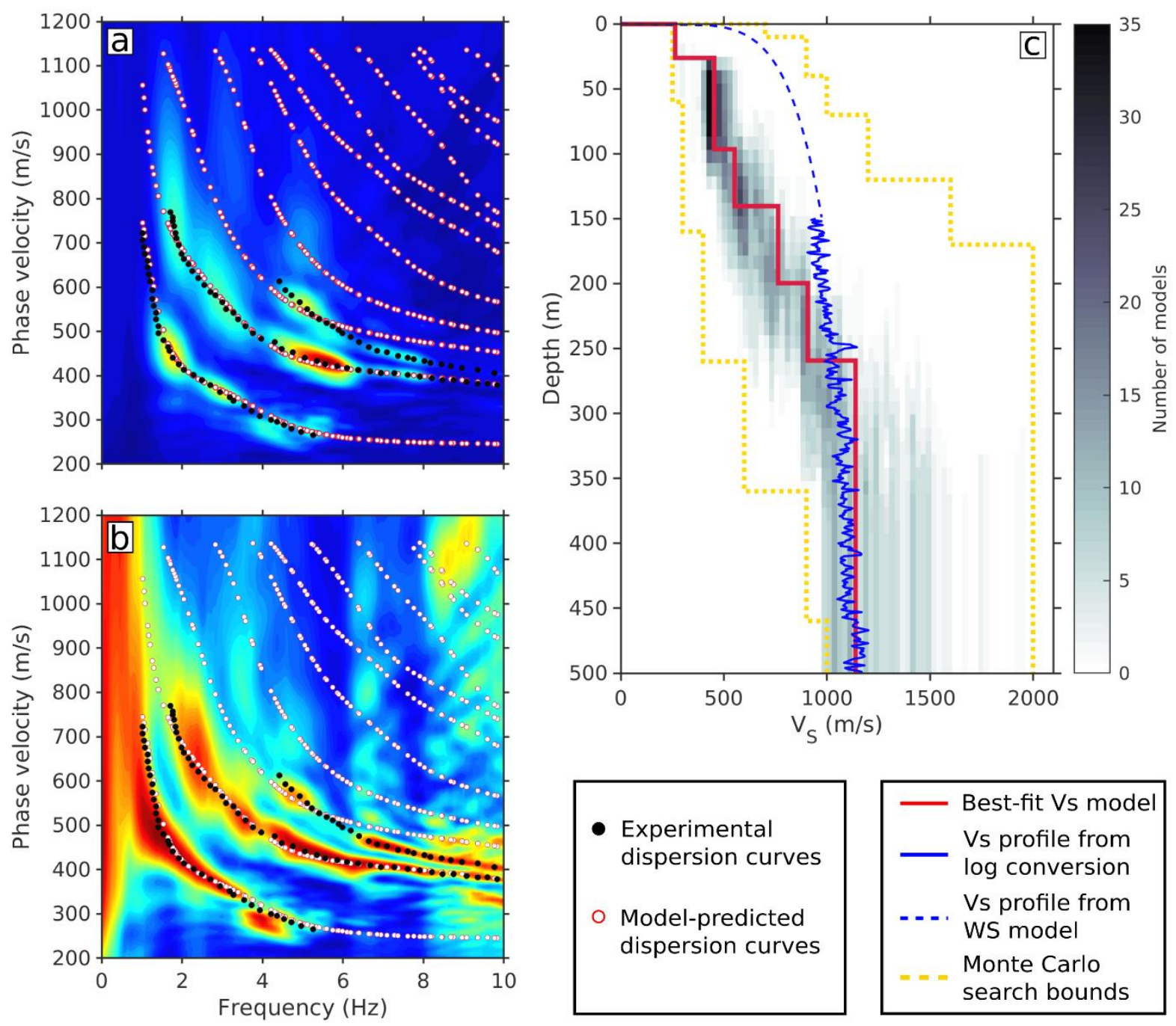

Figure 7. Results of multimodal inversion of the analyzed $1 \mathrm{~km}$-long virtual shot gather. (a) Amplitude normalized dispersion spectra in the frequency-velocity domain. Experimental (black) and model-predicted (white/red) dispersion curves. (b) As for (a) but dispersion spectrum is frequency normalized. (c) Comparison of inverted velocity model with average $V_{s}$ converted sonic well log. Number of models within bins of $5 \mathrm{~m}$ in depth by $25 \mathrm{~m} / \mathrm{s}$ in $V_{s}$ is shown for the top $0.1 \%$ best-fit models as a measure of uncertainty. Model bounds are also illustrated. 
In order to evaluate the applicability of DAS ambient noise analysis for imaging at intermediate scales, we compare our $V_{s}$ model with the integrated $V_{s}$ model converted from well log data as described in the previous section. Our results show that the inverted velocity structure agrees with the converted well log $\mathrm{V}_{\mathrm{s}}$ profile (Figure $7 \mathrm{c}$ ). Our model can capture the increasing velocity gradient described by the log data and matches the very little velocity variation at depth. At depths between $150 \mathrm{~m}$ and $250 \mathrm{~m}$, our best-fit model predicts shear-wave velocities that are slightly lower than those defined by the converted well-logs but fall within the uncertainty bounds. Well log data for depths shallower than $150 \mathrm{~m}$ are not available, which again highlights the utility of dark fiber DAS datasets to retrieve subsurface velocity information at high resolution. As described in the previous section, the dashed line illustrated here at those shallower depths corresponds to the Vs trend estimated by the WS model. The model predicts velocities that are higher than our inverted velocity structure. Subsurface properties at these depths, however, are highly variable. It is expected that, due to many simplifying assumptions, the WS model is not able to adequately capture the complexity of properties at these depths, resulting in a discrepancy between the two estimated profiles. More detailed information on lithology, porosity, water saturation, etc. at these depths and the application of a more sophisticated model for the shallower section of the profile would help alleviate this issue.

\section{Discussion}

Our study illustrates that DAS datasets acquired using existing telecommunication networks are suitable for applying ambient noise analysis to image the top several hundreds of meters of the subsurface. To date, only a few works have focused on investigating the subsurface between several tens of meters to several hundreds of meters using ambient noise approaches. Some recent examples include applications such as reservoir-scale imaging and monitoring (De Ridder \& Biondi, 2013; Mordret et al., 2014), landslide imaging (Renalier et al., 2010) and basin-scale groundwater monitoring (Clements \& Denolle, 2018). This lack of intermediate-scale studies is mainly caused by the paucity of noise sources between the microseisms band and higher frequency infrastructure noise sources, as well as the absence of appropriate recording geometries. As previously discussed, waves with frequencies between $0.5 \mathrm{~Hz}$ and 1-2 $\mathrm{Hz}$ are needed to sample depths between $100 \mathrm{~m}$ and $\sim 1 \mathrm{~km}$ (Figure $3 \mathrm{~b}$ ). In our investigation, we have shown that railway activity generates enough energy at these frequencies; DAS arrays located along or nearby railway tracks are suitable for recovering this noise. Along with this lower frequency component, DAS also allows for recording waves at the traffic frequency band, which enables high-resolution imaging of the shallow (top tens of meters) subsurface. Low frequency components are better recovered when cross-correlating noise at receivers separated by long offsets. In contrast, high frequency surface waves scatter off of near-surface features and attenuate rapidly; dense receiver spacing is required in order to fully capture them. In our study we have proven that DAS recorded on dark fiber meets both requirements, enabling the acquisition of high-quality, broadband ambient noise datasets at unprecedented spatial resolution for distances of several kilometers without the necessity of sensor installation or a power source.

Interesting applications of retrieving shear-wave velocity structure at depths of hundreds of meters include their use in seismic reflection processing routines. First, accurate velocity models at these depthscales and spatial density would be useful for precise S-wave static corrections. When the shallow velocity model at a site is not known, corrections are applied using constant velocities. In complex environments, 
this simplification can result in significant distortion of reflector geometries (Yilmaz, 2001). Secondly, such velocity models could potentially be used in later migration steps, which are indispensable for the correct re-location of imaged structures. Lastly, the combination of shallow and intermediate depth $\mathrm{V}_{\mathrm{s}}$ models should find application in understanding earthquake ground motion, particularly in basins where the combination of basement depth as well as near-surface soil properties are required for prediction of amplification and structure performance. Ultimately, the potential of combining dark fiber DAS datasets with ambient noise analysis for intermediate depth imaging, demonstrated in this study, paves the way to efficient high-resolution imaging at a regional scale. Recent studies in the field of ambient seismic noise interferometry have demonstrated that not only surface waves but also body waves can be recovered from noise recordings and used for seismic reflection imaging and P-wave tomography (Draganov et al., 2007; Ryberg, 2011; Nakata et al., 2015; Nakata et al., 2016). In an interferometric experiment carried out in the Sirte basin in Libya using a classical geophone array and 11 hours of ambient seismic noise at high frequencies $(6-24 \mathrm{~Hz})$, the authors are able to retrieve a reflection image of the subsurface that compares to datasets acquired using active source data down to $1 \mathrm{~s}$ two-way traveltime (Draganov et al., 2009, 2013). Within the Sacramento basin, most academic geophysical works have focused on characterizing the basement and crustal structure of the Great Valley forearc basin (e.g. Godfrey et al., 1997; Constenius et al., 2000), whereas a few others have investigated the stratigraphic architecture of the Jurassic-Cretaceous Great Valley Group (Williams \& Graham, 2013). The acquisition of DAS-based ambient noise data at unprecedented spatial resolution would provide means to characterize the stratigraphic framework and structure of the youngest (Paleogene-Quaternary) sedimentary sequences of the basin infill. With the current dark fiber infrastructure, much of the length of the Sacramento basin could be probed using only 4 independent interrogator units (Ajo-Franklin et al., 2019). Investigations of this caliber are rarely feasible with conventional sensors due to instrument, deployment and maintenance costs. This approach can be applied to other geological structures and environments where conventional deployments are challenging or costly, such as basin-scale mapping of geothermal systems, reservoir characterization or hazard evaluation in urban areas.

\section{Conclusions}

This study shows that ambient seismic noise interferometry can be applied to DAS datasets acquired in existing telecommunication networks to retrieve shear-wave structure down to depths of $500 \mathrm{~m}$. DASbased ambient seismic noise data were acquired along a $23.29 \mathrm{~km}$ long dark fiber network that crosses part of the Sacramento Basin between northwest Sacramento and the city of Woodland for a period of approximately 6 months. Noise originating from rail traffic in-line with the fiber array proved to be the most energetic and broadband noise source and is exploited to perform interferometric analysis and inversion of surface wave data to retrieve one-dimensional shear-wave velocity models beneath the array. Results of a $1 \mathrm{~km}$-long section located in the southern end of the array reveal that we can resolve subsurface velocity structure down to a depth of $500 \mathrm{~m}$, with increasing uncertainty below a depth of $\sim 300 \mathrm{~m}$. Our resultant S-wave velocity model agrees well with an average $V_{s}$ profile converted from 7 sonic well logs acquired in gas wells in the vicinity of the DAS array. The potential of combining DAS-based seismic datasets acquired in unused telecommunication networks with analysis of ambient seismic noise opens up possibilities for efficient, high-resolution, basin-scale imaging. 


\section{Acknowledgements}

This work was supported by the Laboratory Directed Research and Development (LDRD) Program of Lawrence Berkeley National Laboratory under U.S. Department of Energy Contract No. DE-AC0205CH11231. This research used resources of the ESnet Dark Fiber Testbed, which is supported by the Office of Science of the U.S. Department of Energy under contract DE-AC02-05CH11231. Nate Lindsey was supported by the National Science Foundation Graduate Research Fellowship under Grant No. DGE 1106400. We would like to thank Silixa for long-term support of our DAS acquisition efforts. We would like to thank Dr. Sebastiano Foti (Politecnico di Torino) for providing the original version of the multimodal surface-wave inversion code utilized in our ambient noise analysis as well as pioneering the inversion approach with his collaborators and students. Finally, we would like to thank CenturyLink for providing installation protocol details on the network section utilized in this study. 


\section{Bibliography}

Ajo-Franklin, J. B., Dou, S., Lindsey, N. J., Monga, I., Tracy, C., Robertson, M., Rodríguez Tribaldos, V., Ulrich, C., Freifeld, B., Daley, T., Li, X. (2019). Distributed Acoustic Sensing Using Dark Fiber for Near-Surface Characterization and Broadband Seismic Event Detection. Scientific Reports 9(1328).

Becker, M. W., Ciervo, C., Cole, M., Coleman, T., \& Mondanos, M. (2017). Fracture hydromechanical response measured by fiber optic distributed acoustic sensing at milliHertz frequencies. Geophysical Research Letters, 44(14), 7295-7302. https://doi.org/10.1002/2017GL073931

Bensen, G. D., Ritzwoller, M. H., Barmin, M. P., Levshin, A. L., Lin, F., Moschetti, M. P., Shapiro, N., Yang, Y. (2007). Processing seismic ambient noise data to obtain reliable broad-band surface wave dispersion measurements. Geophysical Journal International, 169, 1239-1260. https://doi.org/10.1111/j.1365246X.2007.03374.X

Brocher, T. M. (2008). Compressional and shear-wave velocity versus depth relations for common rock types in northern California. Bulletin of the Seismological Society of America, 98(2), 950-968. https://doi.org/10.1785/0120060403

Campillo, M., \& Roux, P. (2015). Crust and Lithospheric Structure - Seismic Imaging and Monitoring with Ambient Noise Correlations. In Treatise on Geophysics: Second Edition (Vol. 1, pp. 391-417). Elsevier B.V. https://doi.org/10.1016/B978-0-444-53802-4.00024-5

Campion Jr, J. T. (1980). Conway Ranch gas field. California Division of Oil and Gas Publication TR 24.

Clements, T., \& Denolle, M. A. (2018). Tracking Groundwater Levels Using the Ambient Seismic Field. Geophysical Research Letters, 45, 1-7. https://doi.org/10.1029/2018GL077706

Constenius, K. N., Johnson, R. A., Dickinson, W. R., \& Williams, T. A. (2000). Tectonic evolution of the Jurassic-Cretaceous Great Valley forearc, California: Implications for the Franciscan thrust-wedge hypothesis. Bulletin of the Geological Society of America, 112(11), 1703-1723. https://doi.org/10.1130/0016-7606(2000)112<1703:TEOTJC>2.0.CO;2

Daley, T. M., Freifeld, B. M., Ajo-Franklin, J., Dou, S., Pevzner, R., Shulakova, V., Kashikar, S., Miller, D. E., Goetz, J., Henninges, J., Lueth, S. (2013). Field testing of fiber-optic distributed acoustic sensing (DAS) for subsurface seismic monitoring. The Leading Edge, (June). https://doi.org/S0016-6480(10)00349-7 [pii]10.1016/j.ygcen.2010.10.003

Daley, T. M., Miller, D. E., Dodds, K., Cook, P., \& Freifeld, B. M. (2016). Field testing of modular borehole monitoring with simultaneous distributed acoustic sensing and geophone vertical seismic profiles at Citronelle, Alabama. Geophysical Prospecting, 64(5), 1318-1334. https://doi.org/10.1111/13652478.12324

Dou, S., Lindsey, N., Wagner, A. M., Daley, T. M., Freifeld, B., Robertson, M., Peterson, J., Ulrich, C., Martin, E.R., Ajo-Franklin, J.B. (2017). Distributed Acoustic Sensing for Seismic Monitoring of the Near Surface: A Traffic-Noise Interferometry Case Study. Scientific Reports, 7(1), 1-12. https://doi.org/10.1038/s41598017-11986-4

Draganov, D., Campman, X., Thorbecke, J., Verdel, A., \& Wapenaar, K. (2009). Reflection images from ambient seismic noise. Geophysics, 74(5), A63-A67. https://doi.org/10.1190/1.3193529 
Draganov, D., Campman, X., Thorbecke, J., Verdel, A., \& Wapenaar, K. (2013). Seismic exploration-scale velocities and structure from ambient seismic noise $(>1 \mathrm{~Hz})$. Journal of Geophysical Research:Solid Earth, 118, 4345-4360. https://doi.org/10.1002/jgrb.50339

Draganov, D. S., Wapenaar, K., Mulder, W., Singer, J., \& Verdel, A. (2007). Retrieval of reflections from seismic background-noise measurements. Geophysical Research Letters, 34(4), 2-5. https://doi.org/10.1029/2006GL028735

Godfrey, N. J., Beaudoin, B. C., \& Klemperer, S. L. (1997). Ophiolitic basement to the Great Valley forearc basin, California, from seismic and gravity data: Implications for crustal growth at the North American continental margin. Geological Society Of America Bulletin, (12), 1536-1562. https://doi.org/10.1130/0016-7606(1997)109<1536

Hartog, A. H., Rao, Y.-J., Ran, Z.-L., Gong, Y., Güemes, A., \& Sierra Perez, J. (2017). An Introduction to Distributed Optical Fibre Sensors. (A. H. Hartog, Ed.). Boca Raton, Florida: Taylor and Francis Group.

Hunter, W. A., Kenworthy, L. G., \& Bowersox, J. R. (1984). Geology of the Todhunters Lake Gas Field. In A. A. Almgren \& P. D. Hacker (Eds.), Paleogene Submarine Canyons of the Sacramento Valley, California AAPG Pacific Section (Vol. 1, pp. 151-163).

Inbal, A., Cristea-Platon, T., Ampuero, J., Hillers, G., Agnew, D., \& Hough, S. E. (2018). Sources of LongRange Anthropogenic Noise in Southern California and Implications for Tectonic Tremor Detection. Bulletin of the Seismological Society of America, 108(6), 3511-3527. https://doi.org/10.1785/0120180130

Jousset, P., Reinsch, T., Ryberg, T., Blanck, H., Clarke, A., Aghayev, R., Hersir, G.P., Henninges, J., Weber, M., Krawczyk, C.M. (2018). Dynamic strain determination using fibre-optic cables allows imaging of seismological and structural features. Nature Communications, 9(2509). https://doi.org/10.1038/s41467018-04860-y

Kaufmann, R. D., Xia, J., Benson, R. C., Yuhr, L. B., Casto, D. W., \& Park, C. B. (2005). Evaluation of MASW Data Acquired with a Hydrophone Streamer in a Shallow Marine Environment. Journal of Environmental \& Engineering Geophysics, 10(2), 87-98. https://doi.org/10.2113/jeeg10.2.87

Li, H., Bernardi, F., \& Michelini, A. (2010). Surface wave dispersion measurements from ambient seismic noise analysis in Italy. Geophysical Journal International, 180(3), 1242-1252. https://doi.org/10.1111/j.1365-246X.2009.04476.x

Li, Z., \& Zhan, Z. (2018). Pushing the limit of earthquake detection with distributed acoustic sensing and template matching: a case study at the Brady geothermal fiel. Geophysical Journal International, 215, 1583-1593.

Lindsey, N. J., Martin, E. R., Dreger, D. S., Freifeld, B., Cole, S., James, S. R., Biondi, B.L., Ajo-Franklin, J.B (2017). Fiber-Optic Network Observations of Earthquake Wavefields. Geophysical Research Letters, 44(23), 11,792-11,799. https://doi.org/10.1002/2017GL075722

Maraschini, M., \& Foti, S. (2010). A Monte Carlo multimodal inversion of surface waves. Geophysical Journal International, 182(3), 1557-1566. https://doi.org/10.1111/j.1365-246X.2010.04703.x

Maraschini, M., Ernst, F., Foti, S., \& Socco, L. V. (2010). A new misfit function for multimodal inversion of surface waves. Geophysics, 75(4), G31-G43. https://doi.org/10.1190/1.3436539 
Mateeva, A., Lopez, J., Mestayer, J., Wills, P., Cox, B., Kiyashchenko, D., Yang, Z., Berlang, W., Detomo, R., Grandi, S. (2013). Distributed acoustic sensing for reservoir monitornig with VSP. The Leading Edge, (October), 3-7. Retrieved from http://library.seg.org/doi/10.1190/INT-2014-0248.1

Mavko, G., Mukerji, T., \& Dvorkin, J. (1998). The rock physics handbook. Cambridge University Press.

Mindlin, R. D. (1949). Compliance of elastic bodies in contact. Journal of Applied Mechanics, 16, 259268.

Molinari, I., Verbeke, J., Boschi, L., Kissling, E., \& Morelli, A. (2015). Italian and Alpine three-dimensional crustal structure imaged by ambient-noise surface-wave dispersion. Geochemistry Geophysics Geosystems, 18(1-2), 1541-1576. https://doi.org/10.1002/2014GC005684.Key

Mordret, A., Landés, M., Shapiro, N. M., Singh, S. C., \& Roux, P. (2014). Ambient noise surface wave tomography to determine the shallow shear velocity structure at Valhall: Depth inversion with a Neighbourhood Algorithm. Geophysical Journal International, 198(3), 1514-1525. https://doi.org/10.1093/gji/ggu217

Nakata, N., Snieder, R., Tsuji, T., Larner, K., \& Matsuoka, T. (2011). Shear wave imaging from traffic noise using seismic interferometry by cross-coherence. Geophysics, 76(6), SA97-SA106. https://doi.org/10.1190/geo2010-0188.1

Nakata, N., Chang, J. P., Lawrence, J. F., \& Boué, P. (2015). Body wave extraction and tomography at Long Beach, California, with ambient-noise interferometry. Journal of Geophysical Research: Solid Earth, 120(2), 1159-1173. https://doi.org/10.1002/2015JB011870

Nakata, N., Boué, P., Brenguier, F., Roux, P., Ferrazzini, V., \& Campillo, M. (2016). Body and surface wave reconstruction from seismic noise correlations between arrays at Piton de la Fournaise volcano. Geophysical Research Letters, 43(3), 1047-1054. https://doi.org/10.1002/2015GL066997

Olmsted, F. H., \& Davis, G. H. (1961). Geologic features and ground-water storage capacity of the Sacramento Valley, California. U.S. Geological Survey Water-Supply Paper 1497, 241.

Park, C. B., Miller, R. D., \& Xia, J. (1999). Multichannel analysis of surface waves. Geophysics, 64(3), 800808. https://doi.org/10.1190/1.1444590

Parker, E. H., \& Hawman, R. B. (2012). Multi-channel Analysis of Surface Waves (MASW) in Karst Terrain, Southwest Georgia: Implications for Detecting Anomalous Features and Fracture Zones. Journal of Environmental \& Engineering Geophysics, 17, 129-150. https://doi.org/10.2113/JEEG17.3.129

Parker, T., Shatalin, S., \& Farhadiroushan, M. (2014). Distributed Acoustic Sensing - a new tool for seismic applications, 32(February), 61-69.

Pepper-Kittredge, O., \& Wilson, M. L. (1984). The Markley Submarine Valley and its Stratigraphic Relationships, Sacramento Valley, California. In A. A. Almgren \& Paul D Hacker (Eds.), Paleogene Submarine Canyons of the Sacramento Valley, California - AAPG Pacific Section (Vol. 1, pp. 81-99).

Quiros, D. A., Brown, L. D., \& Kim, D. (2016). Seismic interferometry of railroad induced ground motions: Body and surface wave imaging. Geophysical Journal International, 205(1), 301-313. https://doi.org/10.1093/gji/ggw033

Renalier, F., Jongmans, D., Campillo, M., \& Bard, P. Y. (2010). Shear wave velocity imaging of the Avignonet landslide (France) using ambient noise cross correlation. Journal of Geophysical Research: Earth Surface, 115(3), 1-14. https://doi.org/10.1029/2009JF001538 
De Ridder, S. A. L., \& Biondi, B. L. (2013). Daily reservoir-scale subsurface monitoring using ambient seismic noise. Geophysical Research Letters, 40(12), 2969-2974. https://doi.org/10.1002/grl.50594

Ryberg, T. (2011). Body wave observations from cross-correlations of ambient seismic noise: A case study from the Karoo, RSA. Geophysical Research Letters, 38(13), 1-5. https://doi.org/10.1029/2011GL047665

Schimmel, M., \& Paulssen, H. (1997). Noise reduction and detection of weak, coherent signals through phase weighted stacks. Geophysical Journal International, 130, 497-505. https://doi.org/10.1111/j.1365246X.1997.tb05664.x

Seats, K. J., Lawrence, J. F., \& Prieto, G. A. (2012). Improved ambient noise correlation functions using Welch's method. Geophysical Journal International, 188(2), 513-523. https://doi.org/10.1111/j.1365246X.2011.05263.x

Shapiro, N. M., Campillo, M., Stehly, L., \& Ritzwoller, M. H. (2005). High-Resolution Surface-Wave Tomography from Ambient Seismic Noise. Science, 307(5715), 1615-1618. https://doi.org/10.1126/science.1108339

Snieder, R., \& Larose, E. (2013). Extracting Earth's Elastic Wave Response from Noise Measurements. Annual Review of Earth and Planetary Sciences, 41(1), 183-206. https://doi.org/10.1146/annurev-earth050212-123936

Walton, K. (1987). The effective elastic moduli of a random pack of spheres. Journal of the Mechanics and Physics of Solids, 35, 213-226.

Williams, T. A., \& Graham, S. A. (2013). Controls on forearc basin architecture from seismic and sequence stratigraphy of the Upper Cretaceous Great Valley Group, central Sacramento Basin, California. International Geology Review, 55(16), 2030-2059. https://doi.org/10.1080/00206814.2013.817520

Wu, H., Wong, W.-F., Yang, Z., Wills, P. B., Lopez, J. L., Li, Y., Blonk, B., Hewett, B., Mateeva, A. (2015). Dual-well 3D vertical seismic profile enabled by distributed acoustic sensing in deepwater Gulf of Mexico. Interpretation, 3(3), SW11-SW25. https://doi.org/10.1190/INT-2014-0248.1

Wu, X., Willis, M. E., Palacios, W., Ellmauthaler, A., Barrios, O., Shaw, S., \& Quinn, D. (2017). Compressional- and shear-wave studies of distributed acoustic sensing acquired vertical seismic profile data. The Leading Edge, 36(12), 987-993. https://doi.org/10.1190/tle36120987.1

Xia, J. (2014). Estimation of near-surface shear-wave velocities and quality factors using multichannel analysis of surface-wave methods. Journal of Applied Geophysics, 103, 140-151. https://doi.org/10.1016/j.jappgeo.2014.01.016

Yang, Y., Ritzwoller, M. H., Lin, F. C., Moschetti, M. P., \& Shapiro, N. M. (2008). Structure of the crust and uppermost mantle beneath the western United States revealed by ambient noise and earthquake tomography. Journal of Geophysical Research: Solid Earth, 113(12), 1-9. https://doi.org/10.1029/2008JB005833

Yilmaz, O. (2001). Seismic data analysis - processing, inversion and interpretation of seismic data. Tulsa: Society of Exploration Geophysics Press. 